\title{
ATRIAL FIBRILLATION AND RENAL DYSFUNCTION: CURRENT STATE OF THE PROBLEM AND THE PROSPECTS OF FURTHER STUDY
}

\author{
Protasov K. V. ${ }^{1}$, Dorzhieva V.Z. ${ }^{1}$, Petuhova E. A. ${ }^{2}$
}

The review of literature is devoted to interrelations between atrial fibrillation (AF) and kidney function. The focus is on the most probable mechanisms of renal dysfunction in patients with atrial fibrillation such as fibrosis, inflammation, neurohormonal activation. The impact of central and renal hemodynamics disorders on chronic kidney disease development in atrial fibrillation patients is under consideration. The problem of atrial fibrillation in end-stage renal disease patients also gets the authors' attention. We identified unresolved issues and the prospects for their further research.

Russ J Cardiol 2016, 4 (132), Engl.: 198-201

http://dx.doi.org/10.15829/1560-4071-2016-4-eng-198-201

Key words: atrial fibrillation, kidney, chronic kidney disease.

${ }^{1}$ Irkutsk State Medical Academy of Continuing Education, Irkutsk; ${ }^{2} \mathrm{NHI}$ Road Clinical Hospital on Irkutsk-passenger station of public corporation Russian Railways, Irkutsk, Russia
Corresponding author. Dorzhieva V.Z. Postgraduate student of Cardiology and Prevention of cardiovascular diseases Chair, Irkutsk State Medical Academy of Continuing Education, e-mail: mer valentina@mail.ru.

$\mathrm{AF}$ - atrial fibrillation, ATII - angiotensin II, CAD - coronary artery disease, $\mathrm{CHF}$ - congestive heart failure, CKD - chronic kidney disease, CRP - C-reactive protein, CVD - cardiovascular disease, DM - diabetes mellitus, GFR glomerular filtration rate, HTN - arterial hypertension, MMPs - matrix metalloproteinases, PIIINP - N-terminal propeptide of type III collagen, RAAS renin angiotensin aldosterone system, SNS - sympathetic nervous system, TGF$\beta 1$ - tissue growth factor $\beta 1$, TIMPs - tissue inhibitors of metalloproteinases, TNF- $\alpha$ - tumor necrosis factor- $\alpha$.

Received February 28, 2016.

Revision received March 03, 2016.

Accepted March 10, 2016

\section{ФИБРИЛЛЯЦИЯ ПРЕДСЕРДИЙ И ФУНКЦИЯ ПОЧЕК: СОВРЕМЕННОЕ СОСТОЯНИЕ ПРОБЛЕМЫ И ПЕРСПЕКТИВЫ ДАЛЬНЕЙШЕГО ИЗУЧЕНИЯ}

Protasov K. V. ${ }^{1}$, Dorzhieva V.Z. ${ }^{1}$, Petuhova E. A. ${ }^{2}$

Обзор литературы посвящен анализу взаимосвязей фибрилляции предсердий и функции почек. Рассмотрены наиболее вероятные механизмы формирования почечной дисфункции при фибрилляции предсердий: фиброз, воспаление, нейрогуморальная активация. Обсуждается роль нарушений центральной и почечной гемодинамики в развитии хронической болезни почек у больных мерцательной аритмией. Освещена проблема фибрилляции предсердий у пациентов с терминальной почечной недостаточностью. Определены нерешенные вопросы и перспективы дальнейших исследований по данной проблеме.

Atrial fibrillation (AF) is revealed in 1-2\% of total population [1]. Severe complications and adverse outcome make AF lead among all arrhythmias, which is responsible for stroke, embolism, heart failure and a two-fold mortality increase [2].

Cardiovascular and renal diseases are known for their close and multifaceted relationship. Cardiovascular disease (CVD) is the most frequent cause of death for patients with chronic kidney disease (CKD). The latter at the same time is an independent risk factor for adverse outcome of coronary artery disease (CAD), arterial hypertension (HTN), congestive heart failure (CHF) [3].

Considerably less investigation is devoted to renal function in AF patients. The most evident reason for such relationship might be the commonness of pathologic processes underlying both AF and CKD, namely, HTN, atherosclerosis and diabetes mellitus (DM) [4]. Yet, the analysis of major prospective researches has shown that such association persists in patients without CVD and DM [5]. Molecular mechanisms have not conclusively been
Российский кардиологический журнал 2016, 4 (132), Англ.: 198-201 http://dx.doi.org/10.15829/1560-4071-2016-4-eng-198-201

Ключевые слова: фибрилляция предсердий, почки, хроническая болезнь почек.

' Иркутская государственная медицинская академия последипломного образования, Иркутск; ${ }^{2}$ Дорожная клиническая больница РЖД, Иркутск, Россия.

revealed to give insight into the reason behind the relationship between AF and CKD including the concomitant CAD and HTN.

Renal function assessment is gaining a particular urgency on the background of wide introduction into clinical practice of new oral anticoagulants for stroke prevention in AF, as their safe administration is closely related to renal function due to a high renal clearance. The present literature review is devoted to the current state of the art.

\section{Renal function at $\mathrm{AF}$}

In patients with $\mathrm{AF}$, the occurrence of CKD is $18-21 \%$ $[6,7]$ while in total population it is $10-13 \%$ [5]. A number of researches have uncovered a direct relationship between AF frequency and severity of kidney dysfunction. Thus, as the glomerular filtration rate (GFR) decreased, the probability of AF development increased. To the contrary, AF presence suggested the most probable occurrence of CKD [5].

In patients with AF coupled with $\mathrm{CHF}$ a noticeable GFR decrease was associated with a high mortality risk [8]. AF presence was related to the increased level of serum 
cystatin C [9], a more precise marker of renal function than creatinine [10]. In CAD patients the decrease of GFR calculated by cystatin $C$ up to $30 \mathrm{ml} / \mathrm{min} / 1.73 \mathrm{~m}^{2}$ and less was followed by a threefold increase in the likelihood of AF development [4].

The direct dependence of albuminuria/ proteinuria degree on AF presence was revealed. Specifically, in patients with $\mathrm{AF}$ on the background of $\mathrm{CAD}$ and $\mathrm{CHF}, \mathrm{AF}$ was linked to proteinuria development [4-6, 11]. In NIIGATA study (2009) proteinuria development risk in AF patients increased 2,2 times [5]. G. E. Gendlin at al. (2010) showed that in patients with permanent AF on the background of CHF albumin excretion with urine was almost two times higher than at sinus rhythm of 31,4 and $16,7 \mathrm{mg} / \mathrm{l}$, respectively [8]. Injury of kidney parenchyma is likely to enlarge as $\mathrm{AF}$ is progressing: in paroxysmal AF proteinuria was found in $8.5 \%$ of cases, whereas in persistent $\mathrm{AF}$ - in 13,7\% [11]. At the same time, some investigations do not give evidence in favour of AF and GFR association [7].

What are the plausible mechanisms of relationship between $\mathrm{AF}$ and renal function? Today there is no a single justified theory providing an explanation for the interdependence of these pathological processes. The analysis of the carried out investigations has made it possible to distinguish three closely interrelated pathophysiological processes that can be responsible for both $\mathrm{AF}$ and CKD pathway. These are tissue fibrosis, inflammation and neurohormonal activation. Besides, AF might be the cause of kidney injury due to changes in central and renal hemodynamics. Conversely, severe uremic poisoning instigates AF development.

\section{Atrial and kidney fibrosis in AF and CKD}

Atrial and kidney fibrosis is a morphological basis for both $\mathrm{AF}$ and $\mathrm{CKD}$. Atrial fibrosis changes the cardiomyocyte electrophysiological properties and therefore becomes a substrate for AF emergence and maintenance [12]. Degradation of extracellular matrix proteins is generally caused by matrix metalloproteinases (MMPs). Thus, MMPs regulate the exchange of matrix, catalysing the breakdown of its components and changing the activity of growth factors and signalling molecules [13]. MMPs activity varies with recurrent rhythm disturbance including AF. In paroxysmal and persistent AF patients, MMP-9 level was twice as high while in permanent AF patients it was more than threefold in comparison to the healthy [14].

The tissue inhibitors of metalloproteinases (TIMPs) suppress MMP activity that allows treating them as fibrosis indicators. Reduced TIMP-4 and TIMP-1 levels are found to be associated with AF presence [15]. Obviously, a high MMP-9 activity and/or a drop in TIMP-1 regulation account for the excessive stimulation of collagen synthesis in the myocardium, which facilitates the atrial fibrosis formation and instigates AF development. Yet, the lack of tissue specificity of the markers in question does not permit to assert conclusively that their levels are related to atrial fibrosis rather than to fibrosis on the whole [16].
In kidneys over the whole nephron length, MMPs encoded by MMP-2, MMP-3, MMP-9 genes are revealed [17]. A number of researches have noted the link of MMP2, MMP-9 activity variations and their TIMP-1, TIMP-2 tissue inhibitors with kidney fibrosis [18]. The increase in MMP-9 activity associated with microalbuminuria has been ascertained as well $[17,18]$.

Transforming tissue growth factor $\beta 1$ (TGF- $\beta 1$ ) is proinflammatory cytokine. Its excess expression stimulates the fibroblasts growth, extracellular matrix synthesis and fibrosis progressing. The level of TGF- $\beta 1$ in AF patients is known to be higher than in patients with sinus rhythm [19]. This, however, is inconsistent with the data of Cardiovascular Health Study (CHS, 2014) according to which the growth of TGF- $\beta 1$ was not associated with the new AF cases in the elderly [20]. On the other hand, it boosts glomerulosclerosis and interstitial fibrosis [21]. An only study on animals concerning the AF and kidney fibrosis interrelation showed that induced AF paroxysm raised TGF- $\beta 1$ level in renal tissue [22].

$\mathrm{N}$-terminal propeptide of type III collagen (PIIINP) accounts for the collagen III content and is considered lately as a fibrosis marker [23]. The level of PIIINP in AF patients was higher than in patients with sinus rhythm. The increase of PIIINP in blood was suggested as a predictor of arrhythmia recurrence after cardioversion [24]. At the same time, a high concentration of PIIINP in urine was observed in the tubulointerstitional fibrosis cases. A double gain in PIIINP in urine regardless of GFR and albuminuria severity was followed by acceleration rate of CKD progressing in 1.2 times [25].

The data presented allow some fibrosis indicators (MMP, TIMP, TGF- $\beta 1$ и PIIINP) to be considered as common kidney injure and AF markers though no special investigations were conducted earlier to substantiate this hypothesis.

\section{Atrial inflammation and CKD}

A convincing body of evidence has been amassed for inflammation in the atrial myocardium of the AF patients. The extent of structural changes in atria was found to depend on the level of inflammation markers [26]. AF presence as well as the risk of its recurrence after cardioversion were linked to the rise in high-sensitive $\mathrm{C}$-reactive protein (CRP) [27]. In paroxysmal AF patients the level of tumor necrosis factor- $\alpha$ (TNF- $\alpha$ ) in blood was 3.8 times higher than in the ones with sinus rhythm [28]. The interleukin-15 level directly correlated to the number of AF episodes [29]. Regaining the sinus rhythm resulted in the statistically significant decrease of elevated levels of inflammation markers [26].

However, cause-effect relationship between inflammation and AF has not been ultimately ascertained. The inflammatory cell infiltration and calcium overload are considered to contribute to atrial oxidative stress and fostering the atrial fibrosis development [12]. This may upset the mechanical and electrophysiological functions of atrium. Yet, the first 
paroxysm of arrhythmia is believed to occur independently while inflammation supports arrhythmia recurrence [26]. Finally, there is evidence for inflammation being a consequence of $\mathrm{AF}$, whereas the rise in the inflammatory markers is due to the disease underlying $\mathrm{AF}$ development [30]. Inflammation does not seem to be the sole reason for atrial arrhythmogenic but is most likely to play a part in building up "readiness" for AF paroxysm development [26].

At the same time, the rise in the inflammatory markers is also observed in CKD patients [31]. CRP level has been found to correlate directly with the severity of albuminuria in hypertensive patients [32]. The increase in TNF- $\alpha$ and interleukin 1 and 6 content was associated with both the drop in GFR and the rise in albuminuria [33].

Therefore, there are grounds to believe that subclinical inflammation is one of the reasons for AF and CKD association. Whether it manifests itself as a single systemic process or these are separate unrelated inflammatory changes still remains unclear.

\section{Neurohormonal activation at AF and CKD}

Activation of the renin angiotensin aldosterone system (RAAS) is known to be typical for AF patients. Several mechanisms of structural and electrophysiological atria remodelling under the action of RAAS mediators aldosterone and angiotensin II (ATII) have been described. These are the increase of atrial tissue fibrosis, stretching and dilation of the atria, a direct impact on the ion channel function and cardiomyocyte intercellular interaction [34]. Besides, aldosterone induces local inflammation in coronary artery endothelium and myocardial perivascular spaces [2]. AF patients showed the increase of type 1 receptors to AT II density and a growing level of angiotensin converting enzyme in the left atrial tissue [35].

RAAS activation has been proved for CKD patients. In CKD patients, the plasma aldosterone level was found to grow with the disease worsening [36]. AT II is responsible for the glomerular arterioles spasm, predominantly of the efferent one, bringing about hyperfiltration, glomerular hypertrophy and, as a consequence, focal glomerulosclerosis [37].

It is reasonable to suggest, that the rise in RAAS activity, e.g. in high-renin form of HTN or CHF, stimulating $\mathrm{AF}$ development results in kidney fibrosis. Furthermore, ATII and aldosterone activate $\mathrm{NAD}(\mathrm{P}) \mathrm{H}$ oxidase to promote endothelial dysfunction as well as heart remodelling and kidney damage [38].

An elevated activity of sympathetic nervous system (SNS) can also provoke AF. Excessive catecholamines affecting myocardium and ion transport induce persistent tachycardia, heart rate variability violation and QT dispersion increase. This lowers the threshold of arrhythmias [39].

The role of SNS hyperactivity is also considered for CKD pathogenesis. It is common knowledge that $30 \%$ of norepinephrine excreted in urine and up to $70 \%$ of epinephrine come from blood to kidney. The remaining amount is released directly into the kidney from renal nerve endings. Sympathetic hyperactivity and RAAS acti- vation underlie the glomerular efferent arteriola spasm and hyperfiltration development [40, 41]. Furthermore, catecholamines of high concentration are apt to exert a direct damage on renal interstitium. Parenchymal sclerosis and renal ischemia, in their turn, are primarily responsible for afferent signals to integrating brain nuclei in response to which the synthesis of catecholamines takes place by feedback mechanism [42].

Disorders of intrarenal and systemic hemodynamics in $\mathrm{AF}$ as the reason for renal dysfunction

Kidney embolism is another mechanism of AF negative effect on kidneys with a distinct cause-effect relationship. In population, renal artery embolism is encountered seldom enough. The incidence of peripheral embolism is $0.4 \%$ [43] and that of visceral embolism is $15 \%$ [43]. In AF patients, kidney embolism is registered in $3 \%$ of cases [44]. The most common reason for renal artery embolism is atrial flutter [43]. As a rule, acute renal failure is progressing in the case of large-sized emboli. Microembolization results in gradual decline in renal function due to ischemia, inflammation around emboli and hypertension [45]. However, this phenomenon is quite difficult to verify for lack of marked clinical manifestations, which does not allow us to judge reliably its prevalence.

In $\mathrm{AF}$ cardiac output decreases by 5 to $15 \%$ with further decline in the minute volume of the heart and blood pressure [46] which leads to renal hypoperfusion [47] with the development of ischemia and kidney damage.

\section{$\mathrm{AF}$ in patients with end-stage renal disease}

Of special consideration is the AF, which develops on the background of end-stage renal disease. $11-27 \%$ of patients on chronic haemodialysis are revealed to have a developing $\mathrm{AF}$, which is $10-20$ times more frequent than in general population [48]. Other evidence is reported for $\mathrm{AF}$ to be diagnosed in each sixth dialysis patient. The frequency of arrhythmias in dialysis patients amounts up to $40-76 \%$ [49]. In its turn, mortality of the patients in this category is twice as high as that of the patients without AF [50].

For the most part the researchers are agreed here that namely severe uremia and associated with it oxidative stress are the reasons for AF development [51]. Besides, during haemodialysis AF can be provoked by intradialytic hypotension, haemorrhage, electrolyte shifts as well as iatrogenic factors: receiving of psychotropic, anticonvulsive drugs and certain antibiotics. In the intradialytic interval, arrhythmias can occur because of hyperkalemia. AF is also developing at ineffective dialysis syndrome [52].

\section{Conclusion}

The literature analysis suggests pathogenic relationships to be found between AF and kidney disease. The core of a single pathophysiological mechanism can be attributed to systemic inflammation and neurohormonal activation, primarily RAAS and SNS, being responsible for excessive collagen deposition in the myocardium and electric atrial remodelling on the one hand, and kidney 
fibrosis, intraglomerular hypertension and endothelial dysfunction of glomerular capillaries, on the other. Most often, this mechanism is at work in atherosclerosis, HTN and CHF. AF may result immediately in renal damage due to renal artery embolism. Conversely, severe renal failure

\section{References}

1. ESC 2010 Guidelines for the management of atrial fibrillation - executive summary. Eur Heart J. 2010; 31(19): 2369-429.

2. Angaron P, Dorian P. Antiarrhythmic drugs in atrial fibrillation: do they have a future? Can J Cardiol. 2013; 29: 1158-64.

3. K/DOQI clinical practice guidelines for cardiovascular disease in dialysis patients. Am J Kidney Dis. 2005; 45 (Suppl 3):1-15329

4. McManus DD, Corteville DC, Shlipak MG, et al. Relation of kidney function and albuminuria with atrial fibrillation (from the Heart and Soul Study). Am J Cardiol. 2009; 104 (11): 1551-5.

5. Watanabe $\mathrm{H}$, Watanabe $\mathrm{T}$, Sasaki $\mathrm{S}$, et al. Close bidirectional relationship between chronic kidney disease and atrial fibrillation: the Niigata preventive medicine study. Am Heart J. 2009; 158 (4): 629-36

6. Kobalava ZhD, Kotovskaya YuV, Villeval'de SV, et al. Arterial stiffness and chronic kidney disease: causes and consequences. Ratsional'naya farmakoterapiya $v$ kardiologii. 2014; 10 (1): 83-91. (In Russ).

7. Soliman EZ, Prineas RJ, Go AS, et al. Chronic Renal Insufficiency Cohort (CRIC) Study Group. Chronic kidney disease and prevalent atrial fibrillation: the Chronic Renal Insufficiency Cohort (CRIC). Am Heart J. 2010; 159(6):1102-7.

8. Gendlin GE, Reznik EV, Storozhakov Gl, et al. The relationship of atrial fibrillation and renal function in patients with chronic heart failure. Nefrologiya i dializ. 2010; 12 (4): 255-62. (In Russ.).

9. Liu Ping, Sui Shujian, Xu Dongling, et al. Clinical analysis of association of cystatin c and atrial fibrillation. Russian Journal of Cardiology 2014; 111(7): 17-22.

10. Čabarkapa V. Cystatin $\mathrm{c}-$ more than the marker of the glomerular filtration rate. Med Pregl. 2015; 68(5-6):173-9.

11. Suzuki S, Sagara K, Otsuka T, et al. Estimated glomerular filtration rate and proteinuria are associated with persistent form of atrial fibrillation: analysis in Japanese patients. J Cardiol. 2013; 61 (1): 53-7.

12. Drapkina OM, Emel'yanov AV. Atrial fibrosis is a morphological basis of atrial fibrillation. Ratsional'naya farmakoterapiya v kardiologii. 2013; 9 (4): 417-419. (In Russ.).

13. Niu H., LiY., Li H. et al. Matrix metalloproteinase 12 modulates high-fat-diet induced glomerular fibrogenesis and inflammation in a mouse model of obesity. Sci. Rep. 2016; 29 (6): 20171.

14. Li M, Yang G, Xie B, et al. Changes in matrix metalloproteinase- 9 levels during progression of atrial fibrillation. J Int Med Res. 2014; 42(1): 224-30.

15. Kalogeropoulos AS, Tsiodras S, Rigopoulos AG, et al. Novel association patterns of cardiac remodeling markers in patients with essential hypertension and atrial fibrillation. BMC Cardiovasc Disord. 2011; 28;11:77.

16. Huxley RR, Lopez FL, MacLehose RF, et al. Novel association between plasma matrix metalloproteinase- 9 and risk of incident atrial fibrillation in a case-cohort study: the Atherosclerosis Risk in Communities study. PLoS One. 2013; 8(3): e59052.

17. Bobkova IN, Kozlovskaya LV, Li OA. Matrix metalloproteinases in the pathogenesis of acute and chronic kidney diseases. Nefrologiya i dializ. 2008; 10(2): 105-111. (In Russ.).

18. Bondar' IA, Klimontov WV. The role of matrix metalloproteinases and their inhibitors in the development of renal fibrosis in the patients with diabetes mellitus. Problemy endokrinologii. 2012; 1: 39-44 (In Russ.).

19. Zhang $D$, Liu $X$, Chen $X$, et al. Role of the MAPKs/TGF- $\beta 1 /$ TRAF6 signaling pathway in atrial fibrosis of patients with chronic atrial fibrillationand rheumatic mitral valve disease. Cardiology. 2014; 129(4):216-23.

20. Rosenberg MA, Maziarz M, Tan AY, et al. Circulating fibrosis biomarkers and risk of atrial fibrillation: The Cardiovascular Health Study (CHS). Am Heart J. 2014; 167(5):723-8.

21. Bobkova IN, Chebotareva NV, Kozlovskaya LV, et al. Determination of urinary excretion of monocyte chemotactic protein-1 (MCP-1) and transforming growth factor- $\beta 1$ (TGF$\beta 1)$ is an invasive method of assessment of tubulointerstitial fibrosis with chronic glomerulonephritis. Nefrologiya. 2006; 10(4): 49-55 (In Russ.).

22. Bukowska A, Lendeckel $U$, Krohn A, et al. Atrial fibrillation down-regulates renal neutral endopeptidase expression and induces profibrotic pathways in the kidney. Europace. 2008; 10: 1212-1217.

23. Barzilay Jl, Bůžková P, Kizer JR, et al. Fibrosis markers, hip fracture risk, and bone density in older adults. Osteoporos Int. 2015 Aug 13. [Epub ahead of print].

24. Kawamura M, Munetsugu $\mathrm{Y}$, Kawasaki S, et al. Type III procollagen-N-peptide as a predictor of persistent atrial fibrillation recurrence after cardioversion. Europace. 2012; 14(12): 1719-25.

25. Ix J. H., Biggs M. L., Mukamal K. et al. Urine Collagen Fragments and CKD ProgressionThe Cardiovascular Health Study. J Am Soc Nephrol. 2015; pii: ASN.2014070696. [Epub ahead of print].

26. Harada M, Van Wagoner DR, Nattel S. Role of inflammation in atrial fibrillation pathophysiology and management. Circ J. 2015; 79(3):495-502. may initiate AF. Cause-effect relationship between AF and CKD still remain obscure. The idiopathic AF impact on renal function is not conclusively established, which calls for further specially designed epidemiological and experimental studies.

27. Grigoryan SV, Adamyan KG, Azapertyan LG. The role of inflammatory markers in atria fibrillation: a review Kardiovaskulyarnaya terapiya i profilaktika. 2012; 11(5): $74-8$ (In Russ.).

28. Dedkova AA, Suslova TE, Kologrivova IV, et al. Proinflammatory cytokines and cardiomyocyte autoantibodies in patients with paroxymal supraventricular tachycardias. Sibirskii meditsinskii zhurnal (g. Tomsk). 2010; 25(3): 16-9 (In Russ.).

29. Borowiec A, Kontny E, Smolis-Bąk E, et al. Prospective assessment of cytokine IL-15 activity in patients with refractory atrial fibrillation episodes. Cytokine. 2015; 74(1): 164-70.

30. Alegret JM, Aragones GL. The relevance of the association between inflammation and atrial fibrillation. Eur J Clin Invest. 2013; 43: 324-31.

31. Fu Shihui, Tao Luo, Ye Ping et al. Different types of atrial fibrillation, Renal function and mortality in elderly Chinese Patients with coronary artery disease. Clin Interv Aging. 2014; 9: 301-8.

32. Dmitriev VA, Oshchepkova EV, Titov VN. C-reactive protein and arterial hypertension: are they related? Ter. arkhiv. 2006; 5: 86-9 (In Russ.).

33. Lee BT, Ahmed FA, Hamm LL, et al. Association of $\mathrm{C}$-reactive protein, tumor necrosis factor-alpha, and interleukin-6 with chronic kidney disease. BMC Nephrol. 2015; 16:77.

34. Iravanian S, Dudley SC. The Renin-Angiotensin-Aldosterone System (RAAS) and Cardiac Arrhythmias. Heart Rhythm. 2008; 5(6 Suppl. 1): 12-17.

35. Lévy S. Drug Insight: angiotensin-converting-enzyme inhibitors and atrial fibrillation indications and contraindications. Nat. Clin. Pract. Cardiovasc. Med. 2006; 3 (4): 220-5.

36. Buglioni A, Cannone V, Sangaralingham SJ, et al. Aldosterone Predicts Cardiovascular, Renal, and Metabolic Disease in the General Community: A 4-Year Follow-Up. J Am Heart Assoc. 2015; 4 (12). pii: e002505.

37. Rüster $\mathrm{C}$, Wolf $\mathrm{G}$. The role of the renin-angiotensin-aldosterone system in obesity-related renal diseases. Semin Nephrol. 201333(1): 44-53.

38. Paravicini TM, Touyz RM. NADPHoxidases, reactive oxygen species, and hypertension: clinical implications and therapeutic possibilities. DiabetesCare. 2008; 31(Suppl 2): 170-80.

39. Chinushi M, Izumi D, lijima K, et al. Antiarrhythmic vs. pro-arrhythmic effects depending on the intensity of adrenergic stimulation in a canine anthopleurin-A model of type-3 long QT syndrome. Europace. 2008; 10 (2):249-55.

40. Palatini P., Dorigatti F., Saladini F. et al. Factors associated with glomerular hyperfiltration in the early stage of hypertension. Am J Hypertens. 2012; 25 (9): 1011-6.

41. Agrawal S, Agrawal N, Garg J, et al. Heart failure and chronic kidney disease: should we use spironolactone? Am J Med Sci. 2015; 350 (2): 147-51.

42. Tareeva IE. Nefrologiya. M.: Meditsina; 2000 (In Russ.).

43. Yiin GS, Howard DP, Paul NL, et al. Recent time trends in incidence, outcome and premorbid treatment of atrial fibrillation-related stroke and other embolic vascular events: a population-based study. J Neurol. Neurosurg. Psychiatry. 2015; pii: jnnp-2015-311947. [Epub ahead of print]

44. Camm AJ. 2012 focused update of the ESC Guidelines for the management of atria fibrillation; an update of the 2010 ESC Guidelines for the management of atrial fibrillation developed with the special contribution of the European Heart Rhythm Association Europace. 2012; 14 (10): 1385-413.

45. Makaritsis KP, Liakopoulos V, Leivaditis K, et al. Adaptation of renal function in heart failure. Ren. Fail. 2006; 28(7): 527-35

46. American College of Cardiology Foundation; American Heart Association; European Society of Cardiology; Heart Rhythm Society, Wann L. S., Curtis A. B., Ellenbogen K. A. et al. Management of patients with atrial fibrillation (compilation of 2006 ACCF/AHA/ ESC and 2011 CCF/AHA/HRSrecommendations): a report of the American College of Cardiology/American Heart Association Task Force on practice guidelines. Circulation 2013; 127(18):1916-26.

47. Frea S, Pidello S, Canavosio FG, et al. Clinical assessment of hypoperfusion in acute heart failure - evergreen or antique? Circ J. 2015; 79(2):398-405.

48. Atar I, Kona D, A3ikel S, et al. Frequency of atrial fibrillation and factors related to its development in dialysis patients. Int J Cardiol. 2006; 106(1): 47-51.

49. Narula AS, Jha V, Bali HK, et al. Cardiac arrhythmias and silent myocardial ischemia during hemodialysis. Ren. Fail. 2000; 22(3): 355-68.

50. Shih CJ, Ou SM, Chao PW, et al. Risks of Death and Stroke in Patients Undergoing Hemodialysis With New-Onset Atrial Fibrillation: A Competing-Risk Analysis of a Nationwide Cohort. Circulation. 2016; 133 (3): 265-72.

51. Shen JI, Turakhia MP, Winkelmayer WC. Anticoagulation for atrial fibrillation in patients on dialysis: are the benefits worth the risks? Curr Opin Nephrol Hypertens. 2012; 21(6): 600-6.

52. Huang SY, Chen YC, Kao YH, et al. Renal failure induces atrial arrhythmogenesis from discrepant electrophysiological remodeling and calcium regulation in pulmonary veins, sinoatrial node, and atria. Int J Cardiol. 2016; 1(202): 846-57. 